\title{
THE ADAPTIVE SIGNIFICANCE OF DORSAL SPINE VARIATION IN THE FOURSPINE STICKLEBACK, APELTES QUADRACUS. III. CORRELATED TRAITS AND EXPERIMENTAL EVIDENCE ON PREDATION
}

\author{
D. M. BLOUW* AND D. W. HAGEN \\ Department of Biology, University of New Brunswick, Fredericton, New Brunswick, Canada \\ E3B 6E1
}

Received 22,xi,83

\section{SUMMARY}

Apeltes quadracus is polymorphic for the number of dorsal spines, the variation is heritable, and it is subject to natural selection. Here we investigate selective predation favouring the higher-spined morphs. We predict that populations with greater mean spine number will have longer spines, and we so find. However, the morphs do not differ for spine length within populations, and we conclude that spine number and spine length are selected independently. Populations with greater mean spine number also have longer and deeper bodies, thus having a greater defensive circumference. Again, the morphs do not differ within populations.

Experimental tests demonstrate selective predation on the morphs for four fish species in the laboratory, and for a fish and a bird species in the field. However the experiments also show that:

(a) the higher-spined morphs are not always favoured

(b) vegetation plays a role in selective predation

(c) factors other than spine number are involved

(d) these factors operate before Apeltes is captured (behavioural/ecological)

(e) the factors are correlated with spine number. We conclude that predators are selective agents on the polymorphism, but that the relationship between fitness of the morphs and predators is complex.

\section{INTRODUCTION}

To establish the adaptive significance of variation within species remains a central theme in evolutionary biology. The sticklebacks (Gasterosteidae) are particularly suitable for such study because they are abundant, hardy, and highly variable in a number of easily scored traits. The threespine stickleback (Gasterosteus aculeatus) has been most intensively investigated (Bell, 1976; Wootton, 1976). We have initiated a series of studies on a polymorphism for the number of dorsal spines in the fourspine stickleback (Apeltes quadracus) to provide comparative material.

Our studies (Blouw, 1982; Blouw and Hagen 1981, 1984a, b, c; Hagen and Blouw, 1983) show:

(a) dorsal spine number varies from one to seven (fig. 1), but only the four- and five-spined morphs are abundant, with more extreme phenotypes progressively rarer

(b) the variation in spine number is heritable $\left(h^{2} \approx 0.61\right)$

* Present address: Biology Department, St. Francis Xavier University, Antigonish, Nova Scotia, Canada B2G 1 CO. 


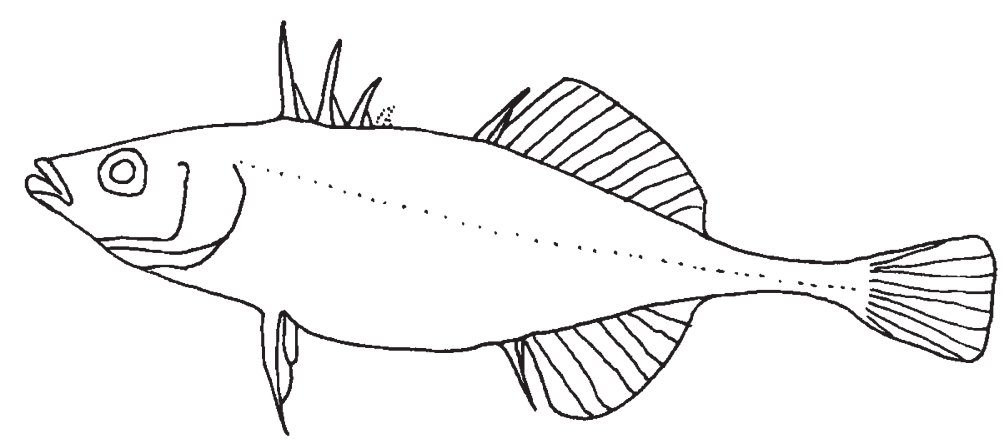

FIG. 1. The four-spined morph of Apeltes quadracus, with a fifth dorsal spine stippled in to show its relative size and position. Dorsal spine number varies from one to seven. The posteriormost dorsal spine is always present and the anteriormost nearly always; polymorphism arises from presence or absence of spines in the intermediate positions.

(c) virtually all of the 570 sites we sampled in the Maritime Provinces of Canada are polymorphic for dorsal spine number

(d) morph frequencies are stable over time and are independent of sex and age and

(e) however morph frequencies are highly differentiated geographically

(f) the geographic variation in morph frequencies is correlated with environmental variables. The environmental correlates of spine variation include predatory fishes, potential competitors, vegetation, physical environment, habitat descriptors, and geographical position (Blouw and Hagen, $1984 b$ ). The correlations between phenotypes and environments occur repeatedly and independently in different geographical areas so we conclude the polymorphism is a consequence of natural selection (Blouw and Hagen, 1984b).

In this paper we focus on predators as selective agents. Our previous analysis (Blouw and Hagen, 1984b) shows that Apeltes has more spines where predatory fishes occur, suggesting they are selective agents favouring the high-spined morphs. We test this hypothesis by searching for covariation between spine number and other traits that function as anti-predator adaptations, and we present experimental evidence from the laboratory and the field. Our results show that predators act as selective agents on the spine morphs, but that the relationship between fitness and predators is complex.

\section{Methods AND Results}

(i) Covariation among funcationally related traits

If predators are selective agents on the polymorphism for dorsal spines, then other aspects of the phenotype that are also adaptations to predators should covary with spine number. Specifically, we expect that spines should be longer where spine number is higher. Thus samples from 45 sites (table 1) were scored for dorsal spine length. Samples were chosen randomly from among our 570 sites with the restrictions that the full range of variation in 
dorsal spine number be represented, that sample size be 35 or greater, and that Pungitius pungitius be adequately represented in each sample to allow a search for interspecific covariation in spine number (see Blouw and Hagen, 1984c). The longest dorsal spine (nearly always the first) was measured with a dissection microscope and ocular micrometer while the spine was extended perpendicular to the body axis.

Spine length is size-dependent, so it was standardised to a body length of $29 \mathrm{~mm}$ for each population to control for size differences among populations. A length of $29 \mathrm{~mm}$ was chosen because it approximates the grand mean length of all samples. The standardised spine lengths were calculated from regression equations of spine length on body length for each sample. Linearity of these intrapopulation relationships between spine length and body length was tested by goodness of fit to successive degrees of polynominal regression. The results are heterogeneous among samples; for 58 per cent of the samples the linear model provides the best fit, for 22 per cent the quadratic is best, for 9 per cent the cubic is best, and for 11 per cent the quartic or a higher model is best. The linear model was used because $\log$ transformation offered no improvement, the increases in $R^{2}$ by fitting higher order models are small (mean increase $=4$ per cent, maximum $=8 \cdot 3$ per cent), and the standardised spine lengths calculated from higher order equations are very similar to those calculated from the linear model. Intrapopulation regressions are coincident (neither slopes nor intercepts differ significantly) for the sexes and between adults and juveniles for most samples, so the sexes and age groups were pooled.

Standardised spine length and mean spine number are positively correlated among populations $(r=0.62 ; p<0.001)$. Thus the hypothesis that higher spine number is an adaptation to selection by predators gains support.

The correlation between spine number and spine length among populations could be due to correlation between these traits within populations (by linkage or pleiotropy). If so, the higher-spined morphs within populations should have longer spines than the lower-spined morphs. Alternatively, if the traits are genetically independent, then interpopulation covariation results from selection on each trait independently.

The coincidence of regressions of spine length on body length within populations was evaluated among morphs for eight samples. The regressions for three- and four-spined fish were compared for two samples and the four- and five-spined morphs were compared for the remaining six. The sexes were treated separately and juveniles were excluded to avoid heterogeneity. The analysis was restricted to eight samples because the others contained too few fish of one morph, or sex ratio was skewed, or both.

For seven of the eight samples the regressions for the morphs are coincident for both sexes. However at Whycocomagh Portage (site 280, table 1) the regressions for the three- and four-spined morphs differ for both sexes. For males spine length is similar among the morphs at about $21 \mathrm{~mm}$ body length, but the regressions diverge at larger sizes with the four-spined morph having progressively longer spines. For females the four-spined morph has longer spines at small body sizes, but the lines intersect with the three-spined having longer spines at larger size. Hence in neither sex does one morph consistently have longer spines.

The coincidence of regressions for seven of the eight samples and the intersection of regressions for the other indicate that the inter-population 


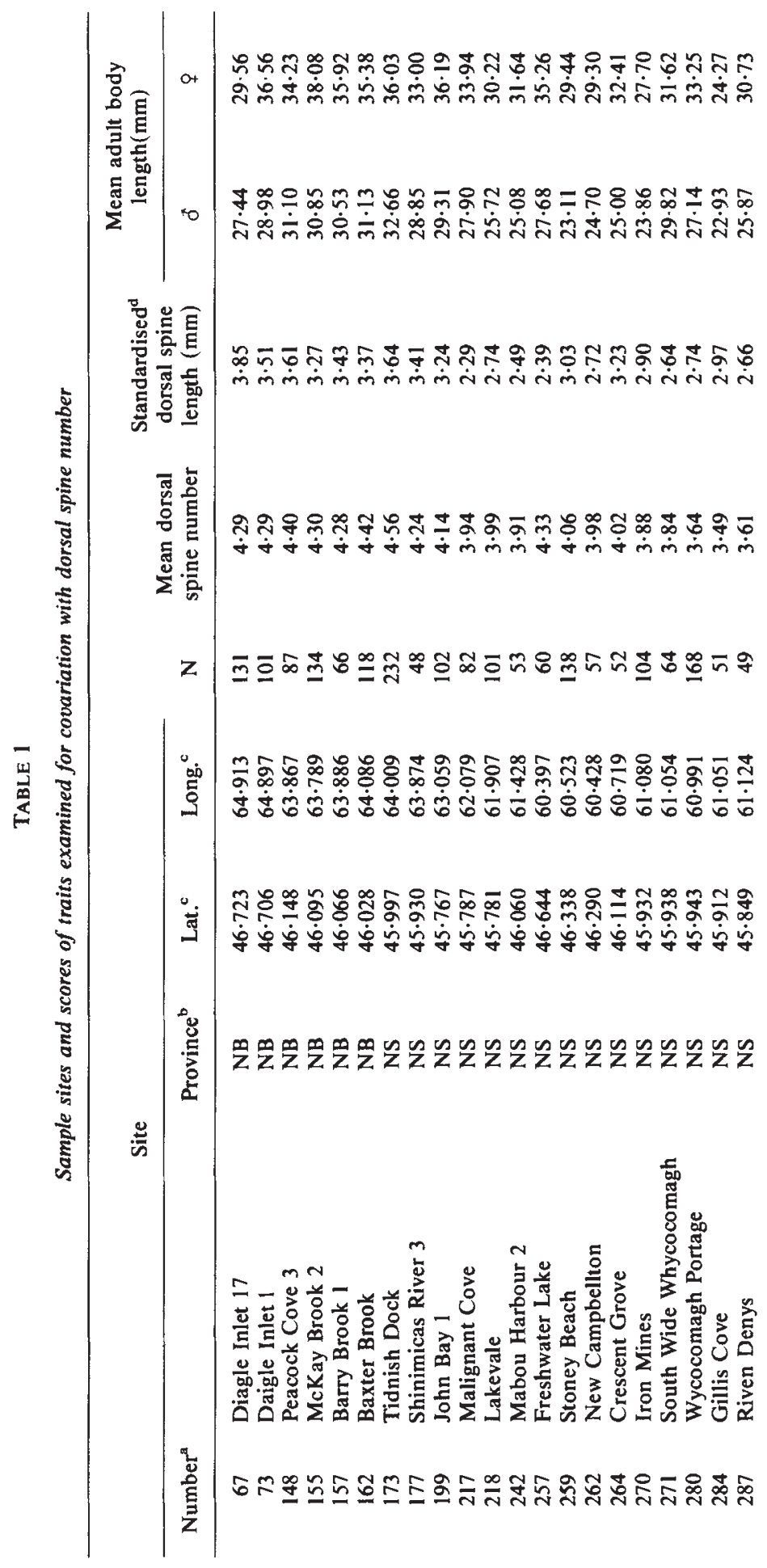




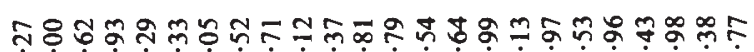

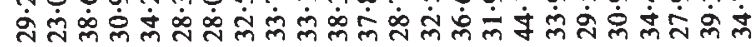

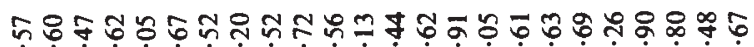

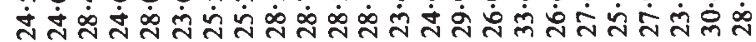

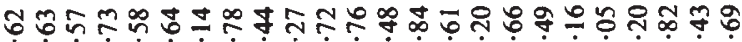
$\dot{N} \dot{N} \dot{N} \dot{N} \dot{N} \dot{N} \dot{m} \dot{N} \dot{m} \dot{m} \dot{N} \dot{N} \dot{N} \dot{N} \dot{n} \dot{N} \dot{m} \dot{N} \dot{m} \dot{m} \dot{m} \dot{N} \dot{N} \dot{N}$

๓

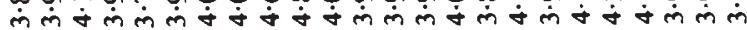

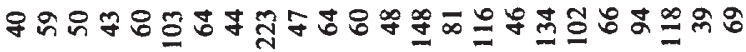

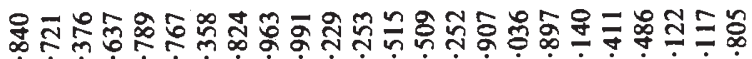

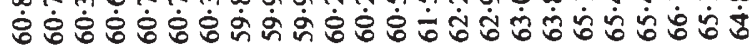

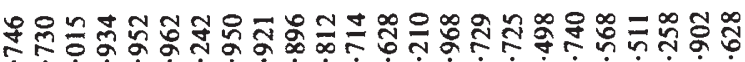

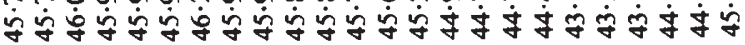

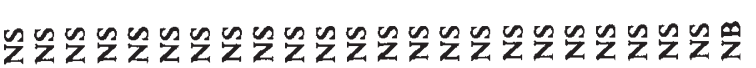

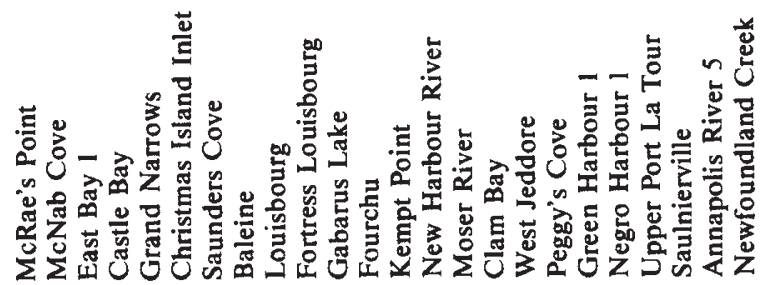

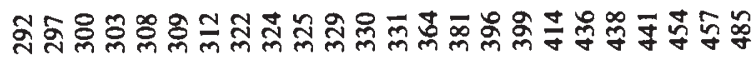


correlation between spine length and spine number is not due to intrapopulation covariation between the traits. Thus they are probably under independent genetic control, and selection acts independently for longer spines in those environments where it favours more spines.

Body depth and pelvic spine length were measured for 5 populations chosen to represent the full range of variation in spine number, and large sample size. Not surprisingly these traits are strongly correlated with dorsal spine length (table 2). All are also strongly correlated with body length

TABLE 2

Correlation coefficients between body depth $(B D)$, pelvic spine length $(P S L)$, dorsal spine length $(D S L)$, and body length $(B L)$ for samples from 5 widely separated sites. All $P<0.001$

\begin{tabular}{lrcccccc}
\hline \multicolumn{1}{c}{ Site Name } & N & BD-PSL & BD-DSL & BD-BL & PSL-DSL & PSL-BL & DSL-BL \\
\hline Baxter Brook & 118 & 0.79 & 0.81 & 0.94 & 0.95 & 0.82 & 0.82 \\
Tidnish Dock & 119 & 0.86 & 0.77 & 0.95 & 0.89 & 0.86 & 0.78 \\
Whycocomagh Portage & 137 & 0.92 & 0.91 & 0.98 & 0.97 & 0.93 & 0.91 \\
Stoney Beach & 84 & 0.88 & 0.82 & 0.97 & 0.91 & 0.89 & 0.85 \\
Peggy's Cove & 134 & 0.87 & 0.82 & 0.92 & 0.87 & 0.85 & 0.79 \\
\hline
\end{tabular}

(table 2). Increasing body length should therefore increase defense against predators, and mean body length should be positively correlated with mean spine number among populations. The samples for dorsal spine length (table 1) were used to determine if this relationship exists. Males and females were treated separately since they differ in size, and juveniles were excluded. For males there is a highly significant positive correlation $(r=0.53 ; p<$ $0.001)$. For females the correlation is weaker $(r=0.37 ; p<0.025)$, but nevertheless positive and significant. Thus populations with more spines are larger in size and have a greater defensive circumference than populations with fewer spines.

To assess whether this correlation among populations is due to covariation between body length and spine number within populations, adult lengths were compared among morphs (sexes separate) by analysis of variance within each of the eight samples. There is no significant difference in mean length among the morphs for either sex in any sample. Hence the interpopulation correlation between mean body length and mean spine number is produced by independent responses in the traits. Assuming body size is heritable, the correlation between body size and spine number is consistent with the hypothesis that predators are selective agents.

\section{(ii) Experimental evidence for selective predation}

The above evidence strongly suggests that predators are selective agents on the variation in dorsal spines. Laboratory experiments were therefore done to provide a direct test of the hypothesis.

Experimental stocks were from brackish environments and were acclimated to fresh water over several days with virtually no mortality. Adults were held in freshwater flow-through tanks and fed liver brine shrimp and frozen tubifex worms. The experiments were conducted in large aquaria $(500 \mathrm{l})$ at about $17^{\circ} \mathrm{C}$ using slightly brackish water (3\%). Only the four- and 
five-spined morphs were used, they were matched for size $( \pm 2 \mathrm{~mm})$, and were introduced in equal proportions in each experiment. Four predators were used; chain pickerel (Esox niger), redfin pickerel (Esox americanus), yellow perch (Perca flavescens) and brook trout (Salvelinus fontinalis). They were obtained in the field except the trout, which were hatchery reared. The predators were held in flow-through tanks and fed small fish (including sticklebacks) and earthworms, but they were starved for one week prior to use.

The experimental conditions are summarised in table 3. For most experiments either 100 or 200 Apeltes were acclimated to the experimental tank for 7 to 10 days. Predators were then introduced and allowed to feed until approximately half of the Apeltes were taken. The results (table 3) were analysed using the hypergeometric $\chi^{2}$ developed by O'Donald and Pilecki (1970) for selection without replacement from a finite population. In experiments where both males and females were used the pooled results are reported if they are homogeneous for the sexes, otherwise the results are given for males and females separately. In three experiments (15-17) an opaque tube $15 \mathrm{~cm}$ in diameter and long enough to extend from the bottom to above the surface was set in the center of a tank containing a predator, and two Apeltes (one of each morph), were placed in the tube. The prey were allowed to acclimate for 30 minutes before the tube was removed. When one morph was captured and swallowed the other was removed and scored. These results were analysed by the usual $\chi^{2}$ method as each trial is independent.

The results are heterogeneous among experiments (table 3). For 9 experiments predation is selective, but in 3 the four-spined morph had the greater survival rate (contrary to expectation), while in 6 the five-spined morph was favoured. In some cases there is heterogeneity between the sexes, in others not, and there is no consistency in whether predation is selective or nonselective among the experiments for either perch or pickerel. However, one consistent pattern does emerge. When vegetation is present predation is nonselective, but when vegetation is absent predation is selective (in 8 of 9 experiments, table 3 ).

We also have direct evidence for selective predation in nature. Brook trout (Salvelinus fontinalis) were captured by gill net at French Fort Brook, and great blue herons (Ardea herodius) were shot at Big Cove (New Brunswick). Grasses predominate at Big Cove while branched vegetation (Potamogeton sp.) predominates at French Fort Brook; filamentous algae are sparse at both sites. Comparisons of morph frequencies in predator guts with those in the populations at large (table 4) show that predators prey selectively. Trout take the four-spined morph in excess (which is consistent with the laboratory experiments and expectation from the phenotypeenvironment correlations), but herons take the five-spined morph in excess. We conclude that selective predation occurs in nature as well as in the laboratory.

\section{Discussion}

Our results provide strong evidence that selection acts on the polymorphism for dorsal spines in Apeltes. However the relationships between phenotypes and fitness are not clear. 


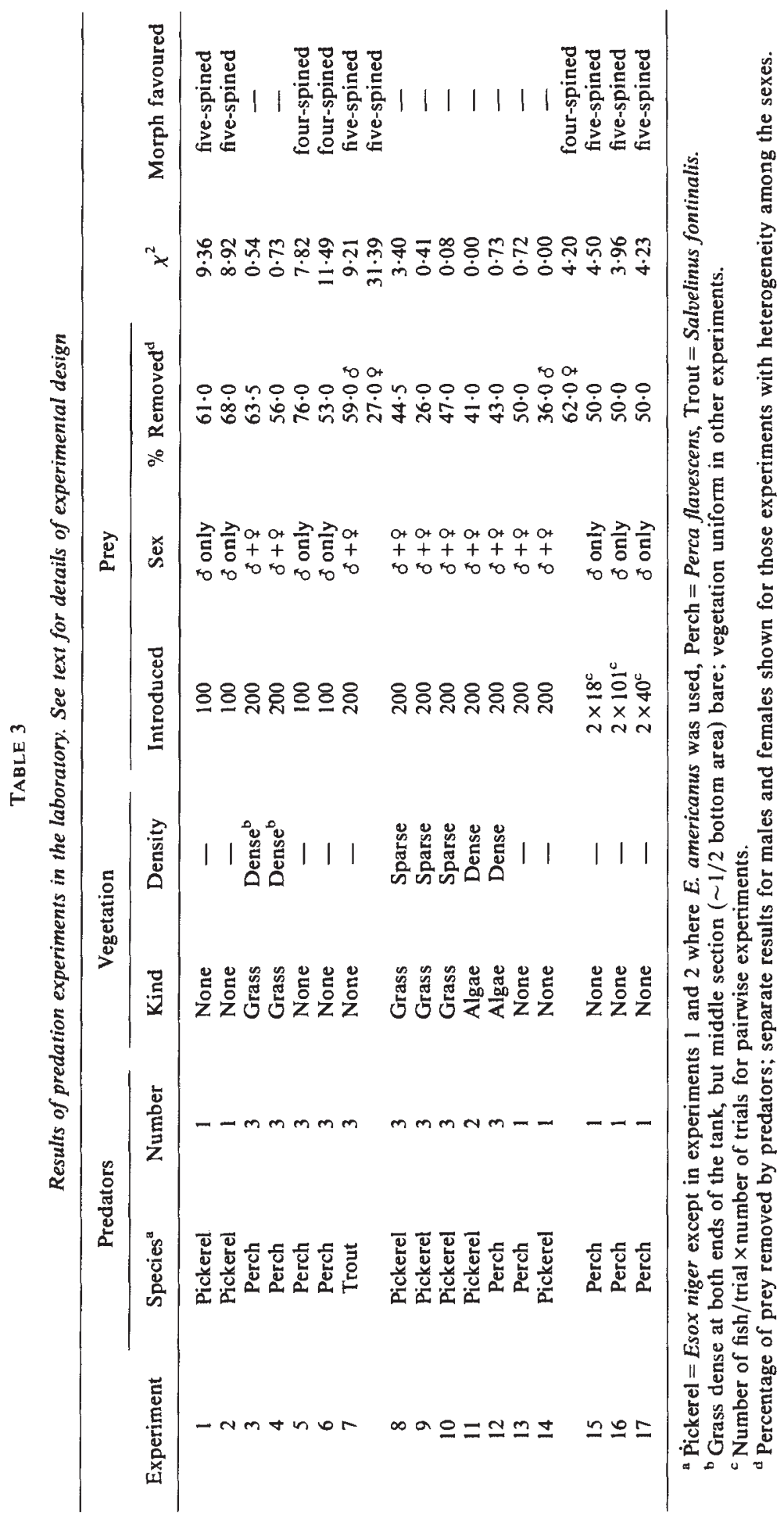


TABLE 4

Results for selective predation by brook trout and great blue herons in the field

\begin{tabular}{|c|c|c|c|c|c|c|c|}
\hline \multirow[b]{2}{*}{ Location } & \multirow[b]{2}{*}{ Predator } & \multicolumn{2}{|c|}{ Gut sample } & \multicolumn{2}{|c|}{$\begin{array}{l}\text { Population } \\
\text { sample }\end{array}$} & \multirow[b]{2}{*}{$\chi^{2}$} & \multirow[b]{2}{*}{$\begin{array}{c}\text { Morph } \\
\text { favoured }\end{array}$} \\
\hline & & $\begin{array}{l}\text { four- } \\
\text { spined }\end{array}$ & $\begin{array}{l}\text { five- } \\
\text { spined }\end{array}$ & $\begin{array}{l}\text { four- } \\
\text { spined }\end{array}$ & $\begin{array}{c}\text { five- } \\
\text { spined }\end{array}$ & & \\
\hline $\begin{array}{l}\text { French Fort } \\
\text { Brook }\end{array}$ & Brook trout & 28 & 14 & 43 & 64 & $7 \cdot 45^{*}$ & five-spined \\
\hline Big Cove 1 & $\begin{array}{l}\text { Great blue } \\
\text { herons }\end{array}$ & 11 & 35 & 114 & 131 & $7 \cdot 19^{*}$ & four-spined \\
\hline
\end{tabular}

${ }^{*} P<0.01$

All the evidence from correlations (Blouw and Hagen, 1984b; herein) indicates that increased spine number is an adaptation to selection by fish predators. Thus increased spine number is correlated with the presence of fish predators, with reduced cover, with increased dorsal spine length, and with increased body length. Since pelvic spine length and body depth are also positively correlated with body length, a suite of at least five traits responds to the presence of predators. However, the laboratory and field experiments with predators suggest that the higher-spined morphs are not always at an advantage. That the fitnesses of the morphs vary is perhaps not surprising. Predator-prey relationships are undoubtedly complex, involving many variables whose interactions are poorly understood.

The phenotype-environment correlations (Blouw and Hagen, 1984b) and laboratory experiments give some clues about the environmental variables which may modify selective predation. The correlations between phenotypes and environment suggest that vegetation plays a role, and this is confirmed by the experiments. But the experimental results indicate that presence and absence of any type of vegetation is important (predation is nonselective in both filamentous algae and grasses; table 3 ) whereas the phenotype-environment correlations (Blouw and Hagen, 1984b) indicate that the type of vegetation is important, but not the quantity (spine number is positively correlated with grasses, negatively correlated with dense filamentous algae, and not correlated with vegetation cover). It may be that our laboratory conditions are a poor approximation to nature, or that the scoring of vegetation in natural environments was inappropriate. The correlations we detect between spine number and bottom composition, bottom hardness, water colour, turbidity and current (Blouw and Hagen, 1984b) suggest these variables may also be relevant. But how they influence the outcome of predation is unclear, so the details of the laboratory and field experiments (direction of selection, relative advantage of the morphs) must be viewed with reservations. The reasons for heterogeneity in which morph is favoured and for the heterogeneity among the sexes are also unknown. Still, the laboratory and field studies do demonstrate selective predation on the morphs.

The mechanism of advantage to the favoured morph is also unclear. The presence of extra spines might confer increased mechanical protection, thus allowing greater opportunity for escape after capture. However, the 
evidence does not support this. Hoogland et al. (1957) have shown that long and robust spines are the most effective defence against predators. This function seems to be served by the invariant (anterior) dorsal spines and the pelvic spines which are the longest and most robust, and which are placed near the deepest point of the body (fig. 1). The polymorphic spines are shorter and more slender, and they are directed posteriorly when erect rather than perpendicularly as would be advantageous to increase circumference or to inflict pain. Furthermore, observations during the pairwise laboratory experiments with perch give no evidence of differential ability of the morphs to escape once they are grasped. Perch often manipulate Apeltes in their mouths, even spit them out and regrasp them, but only twice in 159 trials did the morph that was initially captured eventually escape. One escapee was four-spined and the other five-spined. Clearly this cannot account for the selective predation observed in the experiments. This conclusion may not apply to predators other than perch, nor to conditions which differ from those in the laboratory experiments. But the results do indicate;

(a) that factors other than (or in addition to) mechanical advantage from added spines are involved in selective predation

(b) that the factors operate before Apeltes is grasped

(c) that the factors are correlated with variation in spine number.

Spine length and body size are positively correlated with spine number among populations, but the morphs do not differ in spine length or body size within populations. Since the pairwise predation experiments with perch used prey from a single locality, and since the morphs were matched for size in each trial, the perch cannot be responding to differences in spine length or body size among the morphs.

A similar situation is found in $G$. aculeatus with a polymorphism for lateral plate number, which also has a polygenic basis (Hagen, 1973). Variation in the number of anterior plates confers no obvious mechanical advantage against predation, nevertheless the morphs are subject to strong selective predation (Bell and Haglund, 1978; Gilbertson, 1980; Hagen and Gilbertson, 1973; Moodie, 1972b; Moodie et al., 1973). And, like variation in dorsal spines in Apeltes, lateral plate number in $G$. aculeatus is correlated with spine length and body length among populations (Hagen and Gilbertson, 1972; Moodie, 1972a, b), but not within populations (Bell and Haglund, 1978; Hagen and Gilbertson, 1972; Kynard and Curry, 1976; Moodie, $1972 a$ ). Reimchen (1983) shows that the presence and configuration of some specific plates (those between the dorsal and pelvic spines) contribute to mechanical rigidity of the spines, but this does not explain why plate number is variable. However, evidence is accumulating which suggests there are behavioural correlates of plate number which may explain, at least in part, the differential predation (Huntingford, 1981; Kynard, 1979; Moodie, 1972a, b; Moodie et al., 1973). Behavioural differences have also been found for other polymorphisms in G. aculeatus (Gilbertson, 1980; Larson, 1976; MacLean, 1980; Reimchen, 1980; Semler, 1971) and for a polymorphism in Culaea inconstans (Reist, 1980a, $b$ ). Thus, behavioural differences among phenotypes are common in sticklebacks and they may provide an explanation for the selective predation in Apeltes. Some evidence for behavioural differences exists. Nugent (1977) has shown that the four- and five-spined morphs differ in their distributions with respect to vegetation and depth, 
and the differential sampling of morphs by seine and poison (Blouw and Hagen 1981, 1984a) also suggest such differences.

Although selective predation may result from behavioural differences, we cannot rule out a mechanical advantage of more spines. Such increased mechanical defense against fish predators may be very difficult to detect experimentally (Reimchen, 1980, 1983). Moreover, reduced spine number may be a mechanical adaptation to invertebrate predators, because the spines may serve as holdfasts to these grasping predators (Reimchen, 1980; Reist, 1980b). Thus mechanical attributes of the spines in conjunction with different predator types may account for some of the observed geographic differentiation in morph frequencies (Blouw and Hagen, 1984a).

Acknowledgements. We thank Dr Carl Bursey and Mr Don Love for their help in collecting herons and samples of Apeltes. Financial support was from NSERC grant A9547 to D.W.H. and, while preparing the manuscript, a NSERC postdoctoral fellowship to D.M.B.

\section{REFERENCES}

BELL, M. A. 1976. Evolution of phenotypic diversity in Gasterosteus aculeatus superspecies on the Pacific Coast of Nova Scotia. Syst. Zool., 25, 211-227.

BELL, M. A. AND HAGLUND T. R. 1978. Selective predation of threespine sticklebacks (Gasterosteus aculeatus) by garter snakes. Evolution, 32, 304-319.

BLouw, D. M. 1982. The Adaptive Significance of Polymorphism for Dorsal Spine Number in Apeltes quadracus, and Comparison with Several Coexisting Sticklebacks. Ph.D. thesis, University of New Brunswick, Fredericton.

BLOUW, D. M. AND HAGEN, D. W. 1981. Ecology of the fourspine stickleback, Apeltes quadracus, with respect to a polymorphism for dorsal spine number. Can. J. Zool., 59, 1677-1692.

BLOUW, D. M. AND HAGEN, D. W. 1984a. The adaptive significance of dorsal spine variation in the fourspine stickleback, Apeltes quadracus. 1. Geographic variation in spine number. Can. J. Zool., (in press).

BLOUW, D. M. AND HAGEN, D. W. $1984 b$. The adaptive significance of dorsal spine variation in the fourspine stickleback, Apeltes quadracus. 2. Phenotype-environment correlations. Can. J. Zool., (in press).

BLOUW, D. M. AND HAGEN, D. W. 1984c. The adaptive significance of dorsal spine variation in the fourspine stickleback, Apeltes quadracus. 4. Phenotypic covariation with closely related species. Heredity, 52, 383-396.

GILbERTSON, L. G. 1980. Variation and Natural Selection in an Alaskan Population of the Threespine Stickleback (Gasterosteus aculeatus L.). Ph.D. thesis, University of Washington, Seattle.

HAGEN, D. W. 1973. Inheritance of number of lateral plates and gill rakers in Gasterosteus aculeatus. Heredity, 30, 303-312.

HAGEN, D. W. AND BLOUW, D. M. 1983. Heritability of dorsal spines in the fourspine stickleback. Heredity, 50, 275-281.

HAGEN, D. W. AND GILBERTSON, L. G. 1972. Geographic variation and environmental selection in Gasterosteus aculeatus L. in the Pacific northwest, America. Evolution, 26, 32-51.

HAGEN, D. W. AND GILBERTSON, L. G. 1973. Selective predation and the intensity of selection acting upon the lateral plates of threespine sticklebacks. Heredity, 30, 272-287.

HOOGLAND, R., MORRIS, D. AND TINBERGEN, N. 1956. The spines of sticklebacks (Gasterosteus and Pygosteus) as means of defence against predators (Perca and Esox). Behaviour, 10, 205-236.

HUNTINGFORD, F. A. 1981. Further evidence for an association between lateral scute number and aggressiveness in the threespine stickleback, Gasterosteus aculeatus. Copeia, 1981, 717-720.

KYNARD, B. E. 1979. Nest habitat preference of low plate number morphs in threespine sticklebacks (Gasterosteus aculeatus). Copeia, 1979, 525-528.

KYNARD, B. AND CURRY, K. 1976. Meristic variation in the threespine stickleback, Gasterosteus aculeatus, from Auke Lake, Alaska. Copeia, 1976, 811-813. 
LARSON, G. L. 1976. Social behaviour and feeding ability of two phenotypes of gasterosteus aculeatus in relation to their spatial and trophic segregation in a temperate lake. Can. J. Zool., 54, 107-121.

MACLEAN, J. 1980. Ecological genetics of threespine sticklebacks in Heisholt Lake. Can. J. Zool., 58, 2026-2039.

MOODIE, G. E. E. 1972a. Morphology, life history, and ecology of an unusual stickleback (Gasterosteus aculeatus) in the Queen Charlotte Islands, Canada. Can. J. Zool., 50, 721-732.

MOODIE, G. E. E. 1972b. Predation, natural selection and adaptation in an unusual threespine stickleback. Heredity, 28, 155-167.

MOODIE, G. E. E., MCPHAIL, J. D. AND HAGEN, D. W. 1973. Experimental demonstration of selective predation on Gasterosteus aculeatus. Behaviour, 47, 95-105.

NUGENT, z. 1977. Selective Predation on Apeltes quadracus as a Consequence of Behavioural Differences between Spine Morphs. M.Sc. thesis, University of New Brunswick, Fredericton.

O'DONALD, P. AND PILECKI, C. 1970. Polymorphic mimicry and natural selection. Evolution, $24,395-401$.

REIMCHEN, T. E. 1980. Spine deficiency and polymorphism in a population of Gasterosteus aculeatus: an adaptation to predators? Can. J. Zool, 58, 1232-1244.

REIMCHEN, T. E. 1983. Structural relationships between spines and lateral plates in threespine stickleback (Gasterosteus aculeatus). Evolution, 37, 931-946.

REIST, J. D. 1980a. Selective predation upon pelvic phenotypes of brook stickleback, Culaea inconstans, by northern pike, Esox lucius. Can. J. Zool., 58, 1245-1252.

REIST, J. D. 1980 b. Predation upon pelvic phenotypes of brook stickleback, Culea inconstans, by selected invertebrates. Can. J. Zool., 58, 1253-1258.

SEMLER, D. E. 1971. Some aspects of adaptation in a polymorphism for breeding colours in the threespine stickleback (Gasterosteus aculeatus L.). J. Zool. Lond., 165, 291-302.

wootton, R. J. 1976. The Biology of the Sticklebacks. Academic Press, London. 